MIDPI

MOL2NET, International Conference Series on Multidisciplinary Sciences

sciforum,

\title{
Quantitative Structure-Antileukemic Activity Models of Stilbenoids: A Theoretical Study
}

Adela León Peris (alepe@alumni.ucv.es) ${ }^{a}$, Francisco Torrens Zaragozá (francisco.torrens@uv.es) ${ }^{\mathrm{b}}$, Gloria Castellano Estornell (gloria.castellano@ucv.es) ${ }^{\text {c* }}$

${ }^{a}$ Escuela de Doctorado. Universidad Católica de Valencia San Vicente Mártir, Spain

${ }^{b}$ Institut Universitari de Ciència Molecular. Universitat de València, Spain

${ }^{b}$ Departamento de Ciencias Experimentales y Matemáticas Universidad Católica de Valencia San Vicente Mártir, Spain * Corresponding author.

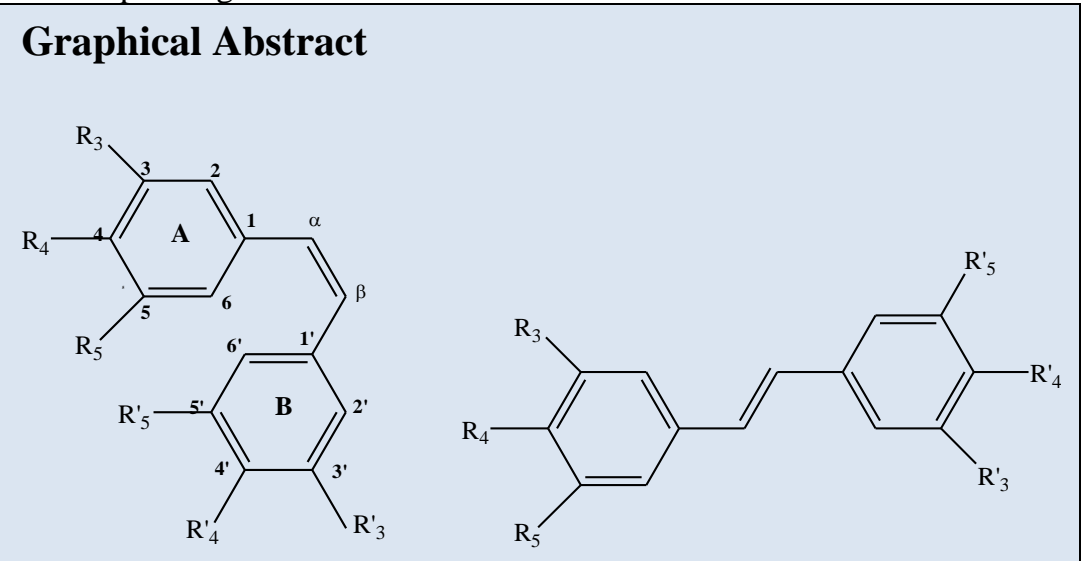

Figure 1. Basic molecular structure of $\boldsymbol{Z}$ and $\boldsymbol{E}$ stilbenes.

Table 1. Structures and anti-leukemic activities on HL60 cells of stilbenes 1

$\begin{array}{lllllllll}\text { STILBENOID } & \mathrm{R}_{3} & \mathrm{R}_{4} & \mathrm{R}_{5} & \mathrm{R}^{\prime}{ }_{3} & \mathrm{R}^{\prime}{ }_{4} & \mathrm{R}^{\prime}{ }_{5} & I C 50^{a} & A C 50^{a}\end{array}$

$\mathrm{Z}$ (cis) /E (trans)

\begin{tabular}{|ll|l|l|l|l|l|l|l|l|}
\hline 1 & $\mathrm{E}$ (trans) & $\mathrm{OH}$ & $\mathrm{H}$ & $\mathrm{OH}$ & $\mathrm{H}$ & $\mathrm{OH}$ & $\mathrm{H}$ & -0.6990 & -1.6990 \\
\hline 2 & $\mathrm{E}$ (trans) & $\mathrm{OMe}$ & $\mathrm{H}$ & $\mathrm{OMe}$ & $\mathrm{H}$ & $\mathrm{OMe}$ & $\mathrm{H}$ & -0.3979 & -0.6021 \\
\hline 3 & $\mathrm{E}$ (trans) & $\mathrm{OMe}$ & $\mathrm{H}$ & $\mathrm{OMe}$ & $\mathrm{OMe}$ & $\mathrm{OMe}$ & $\mathrm{OMe}$ & -1.3424 & -1.6232 \\
\hline 4 & $\mathrm{E}$ (trans) & $\mathrm{OMe}$ & $\mathrm{H}$ & $\mathrm{OMe}$ & $\mathrm{H}$ & $\mathrm{H}$ & $\mathrm{OMe}$ & -1.5682 & -1.8451 \\
\hline 5 & $\mathrm{E}$ (trans) & $\mathrm{H}$ & $\mathrm{OH}$ & $\mathrm{H}$ & $\mathrm{H}$ & $\mathrm{Me}$ & $\mathrm{Me}$ & -0.5441 & -0.7782 \\
\hline 6 & $\mathrm{Z}$ (cis) & OMe & $\mathrm{H}$ & $\mathrm{OMe}$ & $\mathrm{H}$ & $\mathrm{OMe}$ & $\mathrm{H}$ & 0.8239 & 0.6198 \\
\hline 7 & $\mathrm{Z}$ (cis) & $\mathrm{OMe}$ & $\mathrm{H}$ & $\mathrm{OMe}$ & $\mathrm{OMe}$ & $\mathrm{OMe}$ & $\mathrm{OMe}$ & -0.2553 & -0.4150 \\
\hline 8 & $\mathrm{Z}$ (cis) & $\mathrm{OMe}$ & $\mathrm{H}$ & $\mathrm{OMe}$ & $\mathrm{H}$ & $\mathrm{H}$ & $\mathrm{OMe}$ & -0.4472 & -0.7324 \\
\hline
\end{tabular}

${ }^{a}$ Experimental data (in $\mu \mathrm{M}$ ) Simoni D. et al.,2006 Bioorganic \& Medicinal Chemistry Letters, $16,3245-3248$.

\begin{abstract}
Stilbenes are a class of plant secondary metabolites that shows a potential inhibitory effect on cellular events associated with cancer initiation, promotion and progression, as well as displays in vitro growth inhibition in a number of human cancer cell lines. In this report, a quantitative structure-antileukemic relationship (QSAR) of a set of stilbenes is presented. A multiple linear regression approach was adopted to determine the quantitative importance of the combined presence of some variables taken from the ChEMBL database, as well as the antileukemic activity that has been taken from experimental data in the technical literature of anti-proliferative effects (expressed as $\mathrm{IC}_{50}$ ) and apoptotic inducing effects (expressed as $\mathrm{AC}_{50}$ ) of stilbene derivatives on HL60 cells and properties of ChEMBL database. The results for the anti-leukemic activity $\left(\mathrm{pIC}_{50}\right.$ and $\mathrm{pAC}_{50}$ ) show positive correlations with boiling point, and numbers of $\mathrm{Z}($ cis $)$-bonds and methyl groups, while negative correlations with the numbers of methoxy groups in ring $B$ and hydroxy groups. The present results from stilbenes analysis will be useful for the antileukemic activity prediction of new sets of stilbenes, which will prove to be beneficial for health.
\end{abstract}




\section{Introduction}

Stilbenes are plant secondary metabolites consisting of two phenol moieties linked by a C2 bridge (Figure 1). Although the basic stilbene structure is widespread in plants, diverse species-specific substitution patterns exist. Recently, many investigations have been reported on resveratrol, a phenolic stilbene, which has been suggested as a potential chemopreventive agent based on its striking inhibitory effect on cellular events associated with cancer initiation, promotion and progression, and displayed in vitro growth inhibition in a number of human cancer cell lines (Jang et al., 1997; Frémont, 2000; Matsuda et al., 2001; Benlloch M., 2015; Estrela JM., 2017).

The main structural features of stilbenes have to pay attention to some structural requirements for efficient antileukemic activity. Even, the occurrence of substituents with positive mesomeric and inductive electronic effects increases or decreases the bioactivities of the compounds. Moreover, $Z$ (cis) and $E$ (trans) isomers of several analogues of stilbenes have been investigated, especially with regard to the effect of the stereochemistry of the olefinic double bond. It has been postulated and scientifically verified that the $Z$ and $E$ forms of stilbenes elicit different pharmacological activities (Castellano et al, 2014).

The aim of the present report is to predict the anti-leukemic activity of a set of stilbenes (Figure 1 and Table 1), based on their molecular structures and some physical and chemical properties.

\section{Materials and Methods}

A multiple linear regression approach was adopted to determine the quantitative importance of the combined presence of 22 properties or variables taken from the ChEMBL database: full molecular weight (Full mw), acd $\log \mathrm{p}$, rotational bonds number (rtb), heavy atoms, methoxy groups number, hydroxy groups number, methoxy groups in B-ring, $\mathrm{Z}$ (cis) bond, methyl groups number, a logp, boiling point ${ }^{\circ} \mathrm{C} 760 \mathrm{mmHg}$, enthalpy of vaporization, $\mathrm{ACD} / \log \mathrm{P}$, molar volume, polarizability, $\mathrm{ACD} \log \mathrm{D} \mathrm{pH} 7.4, \mathrm{ACD} / \mathrm{KOC} \mathrm{pH} 7.4, \mathrm{ACD} / \mathrm{BCF} \mathrm{pH}$ 7.4, Qed weighted, Lipinski number, surface tension and density. In addition, antileukemic activity data: $\mathrm{pIC}_{50}$ and $\mathrm{pAC}_{50}$ (higher value means higher anti-leukemic activity) on HL-60 cells (Simoni D. et al, 2006).

Principal Component Analysis (PCA), linear regression correlation and multiple linear regression models were performed using SPSS (v. 21.0, IBM Corporation, USA).

\section{Results and Discussion}

The equations of multiple linear regression models to determine the quantitative importance of the combined presence of 22 properties or variables taken from the ChEMBL database with anti-proliferative effects (expressed as $\mathrm{IC}_{50}$ ) and apoptosis inducing effects (expressed as $\mathrm{AC}_{50}$ ) of the stilbene derivatives on HL60 cells were as follows:

pIC50 $=-54.536+[0.137 \times$ Boiling Point $]+[1.143 \times \mathrm{Z}($ cis $)$ bond $]+[2.820 \mathrm{x}$ methyl groups number $]-[3.948 \mathrm{x}$ methoxy groups in B-ring number] - [2.586 $\mathrm{x}$ hydroxy groups number]

Approximation Error Variance: 0.0495

Correlation coefficient (R): 0.999

Fisher ratio (F): 300.676

Durbin-Watson: 1.882

pAC50 $=-58,198+[0,146 \times$ Boiling Point $]+[1,181 \times \mathrm{Z}($ cis $)$ bond $]+[3,131 \times$ methyl groups number $]-[4,174$ $\mathrm{x}$ methoxy groups in B-ring number] - [2.993 $\mathrm{x}$ hydroxy groups number]

Approximation Error Variance: 0.042

Correlation coefficient (R): 1.000

Fisher ratio (F): 534.232

Durbin-Watson: 2.618

In both QSAR models, the standard error of all coefficients is lower that the corresponding value. Both linear regressions indicate that boiling point, Z(cis) bond and methyl groups number increase the antileukemic activity and methoxy groups in B-ring number and hydroxy groups number decrease antileukemic activity. 
Figure 2 shows the clusters obtained for the stilbenes by principal components analysis (PCA). These results are according with experimental data because the stilbenes included in the same class present similar $\mathrm{pIC}_{50}$ and $\mathrm{pAC}_{50}$ values. Class 1 (compounds 2, 6, 7, 8; PC1 $>0,-1<\mathrm{PC} 2<1$ ) includes the compounds with the greatest anti-leukemic activity, most characterized by $\mathrm{Z}$ (cis) bond and the presence at least 3 methoxy groups in the molecule at $(6,7$, 8); class 2 (compound 5; $\mathrm{PC} 1<0, \mathrm{PC} 2<<0$ ) with high anti-leukemic activity, characterized by the presence 2 methyl groups; class 3 (compound $1, \mathrm{PC} 1<0, \mathrm{PC} 2>0$ ) is resveratrol, with medium antileukemic activity and $\mathrm{E}$ (trans) bond; and class 4 (compounds 3, 4; PC1<<0) with low antileukemic activity and $\mathrm{E}$ (trans) bond. The variance explained by PC1 and PC2 is $74,681 \%$ (SPSS).

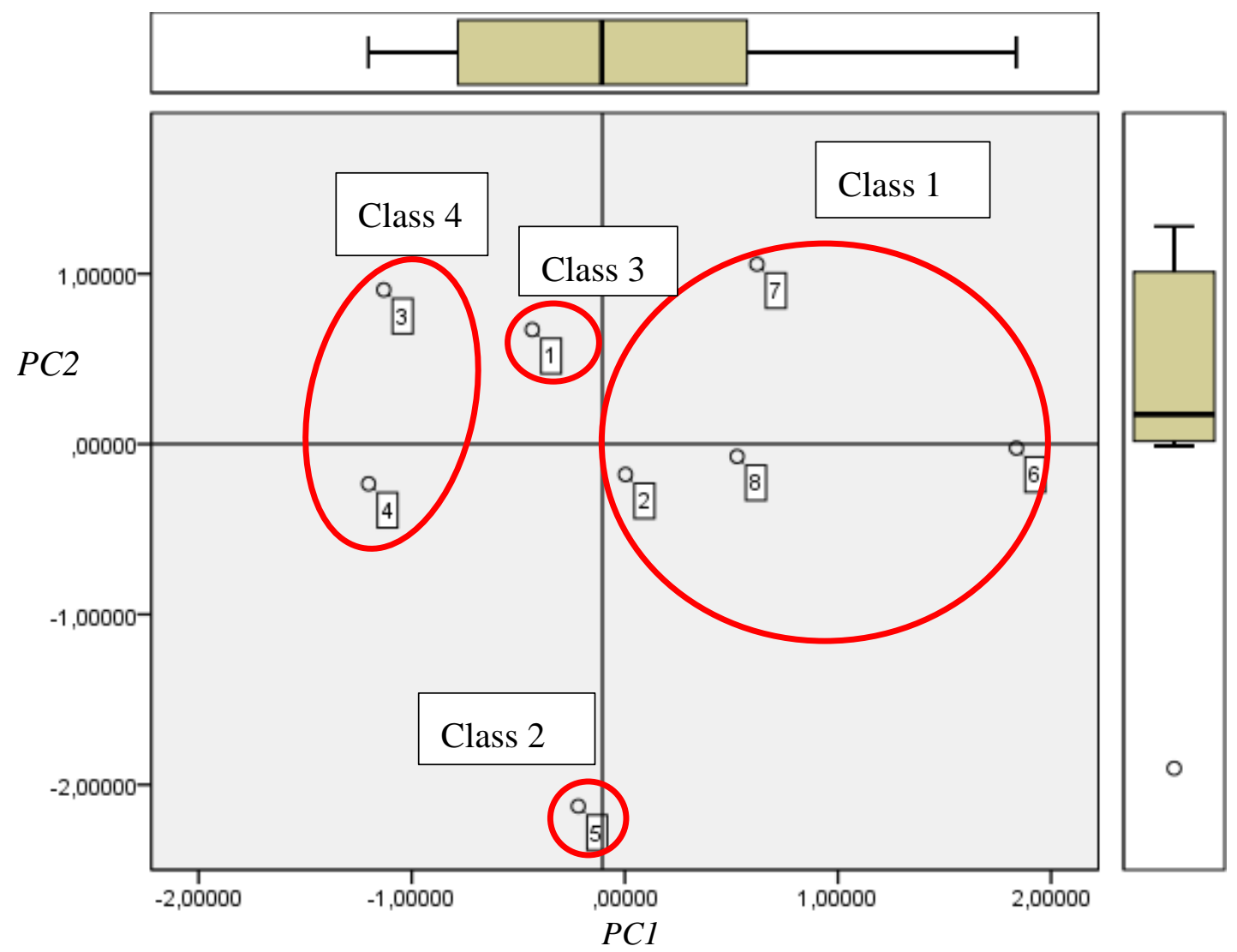

Figure 2. Stilbenes Scores Plot obtained by Principal Component Analysis and their Clusters

Figure 3 shows the loading plot of the variables that have influence in anti-proliferative effects (expressed as pIC ${ }_{50}$ ) and apoptosis inducing effects (expressed as $\mathrm{pAC}_{50}$ ) of stilbene derivatives on HL60 cells. The results are in concordance with the equations obtained in the multiple linear regression. Those properties most distant from point $(0,0)$ are the most important for describing PCs, and those closest to 0,0 are less important. The PC1 $(40,46 \%$ SPSS of the total variance) shows positive loading of $\mathrm{pIC}_{50}, \mathrm{pAC}_{50}, \mathrm{Z}($ cis $)$ bond, methoxyl groups number in $\mathrm{B}$ ring, and boiling point, while negative loading of hydroxyl and methyl groups number. The PC2 (34,23\% SPSS of the total variance) shows positive loading of $\mathrm{Z}$ (cis) bond, methoxyl groups number in B-ring and boiling point, while negative loading of methyl groups number. 


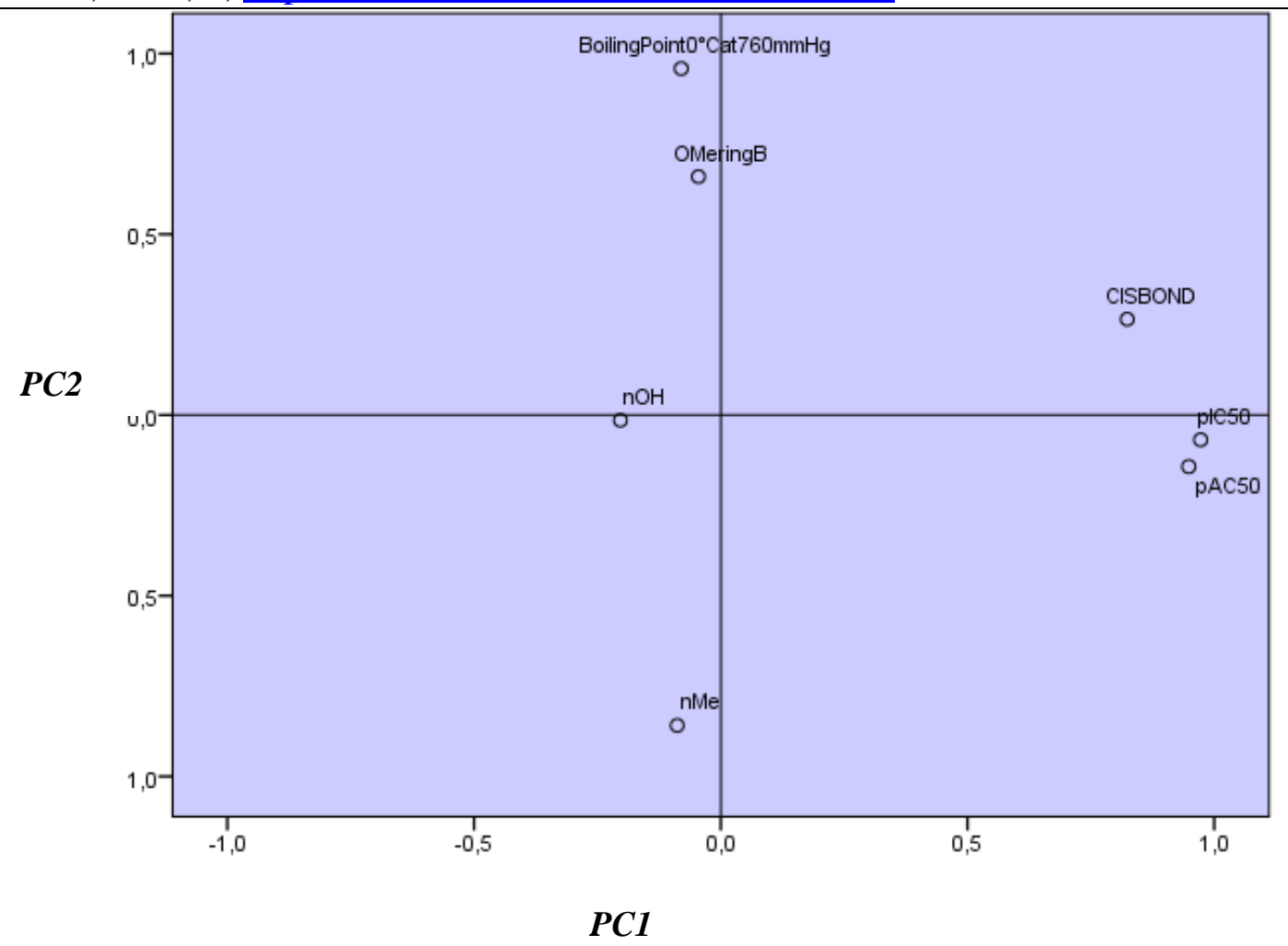

Figure 3 Loading Plot for properties of stilbenes obtained by Principal Component Analysis

\section{References}

Benlloch M., Muriach M., Castellano G., Sancho-Pelluz F.J., González-García E., Flores-Bellver M., Romero F.J. (2015) Role of Lycium Barbarum Extracts in Retinal Diseases. Lycium Barbarum and Human Health, Edited by Chang, Raymond Chuen-Chung, So, Kwok-Fai, chapter 11: pages 153-178; Springer Science+Business Media Dordrecht (2015) ISBN: ISBN 978-94-017-9658-3.

Castellano G., Lara A., Torrens F. (2014) Classification of Stilbenoids compounds by entropy of artificial intelligence. Phytochemistry, 97, 62-69.

Estrela J M, Mena S, Obrador E, Benlloch M, Castellano G, Salvador S, Dellinguer R W. Polyphenolic Phytochemicals in Cancer Prevention and Therapy: Bioavailability versus Bioefficacy. Journal of Medicinal Chemistry , 60, 9413-9436. 10.1021/acs.jmedchem.6b01026.

Frémont L (2000) Biological effects of resveratrol Life Sci 66:663-673.

Jang M, Cai L, Udeani G O, Slowing K U, Thomas C F, Beecher C W W, Fong H H S, Farnworth R N, Kinghorn A D, Metha R G, Moon R C, Pezzuto J M (1997) Cancer chemopreventive activity of resveratrol, a natural product derived from grapes Science 275: 218-220.

Matsuda H, Morikawa T, Toguchida I, Park J Y, Harima S, Yoshikawa M (2001) Antioxidant constituents from rhubarb: structural requirements of stilbenes for the activity and structures of two new anthraquinone glucosides Bioorg Med Chem 9:41-50.

Page R D M Program TreeView (2000), University of Glasgow.

Simoni D., Roberti M., Invidiata FP., Aiello E., Aiello S., Marchetti P., Baruchello R., Eleopra M., Di Cristina A., Grimaudo S., Gebbia N., Crosta L., Dieli F., Tolomeo M. (2006) Stilbene-based anticancer agents: Resveratrol analogues active toward HL60 leukemic cell with non-specific phase mechanism. Bioorganic \& Medicinal Chemistry Letters, 16, 3245-3248. 